Military Technical College Kobry El-Kobbah, Cairo, Egypt

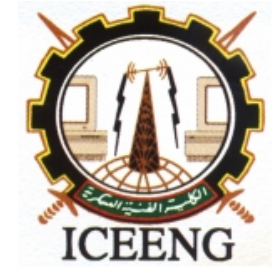

\section{$7^{\text {th }}$ International Conference on Electrical Engineering \\ ICEENG 2010}

\title{
Compact Dual-Band Microstrip Patch Array Antenna for MIMO 4G LTE and WLAN Systems
}

\author{
By
}
M. Ali Soliman*
W. Swelam*
Ali Gomaa**
T. E. Taha***

\section{$\underline{\text { Abstract: }}$}

In this paper, a compact dual-band microstrip patch array antenna for both the MIMO 4G LTE and the WLAN systems is developed. Design simulation and optimization processes are carried out with the aid of the Advanced Design System (ADS) electromagnetic simulator that uses the full-wave Method of Moment (MoM) numerical technique [1]. The losses that are caused by both the substrate and metallization are taken into account during the simulation process. Array compactness was our target during the design process to integrate the array with the new mobile communication equipments.

\section{Keywords:}

Dual-Band Antenna, Microstrip Patch Array Antenna, MIMO Antenna and 4G antenna systems.

* Egyptian Armed Forces.

** Shobraa Faculty of Engineering, Benha University, Cairo, Egypt.

*** Faculty of Electronic Engineering, Menoufia University, Menouf, Egypt. 


\section{Introduction:}

MIMO (Multiple Input Multiple Output) systems have been studied extensively during the recent years. It is clear from the theoretical point of view that the use of MIMO systems increases the capacity of transferred signal as compared to the use of SISO (Single Input Single Output) and SIMO (Single Input Multiple Output) systems [2]. 4G handheld telephones, iphones, and other new compact cellular equipments recommend the use of small-scale, multi-band MIMO antennas [3]. In this paper, a compact 1x4 Uslotted dual-band microstrip linear patch array antenna prototype is designed, fabricated and measured. It covers both the 4G LTE (Long-Term Evolution) and the WLAN (Wireless Local Area Network) bands and can be used in other MIMO antenna applications. Microstrip antenna type is preferable due to its easy fabrication, low cost, small-size, low weigh, integrate-ability and compatibility with standard manufacturing process [4]. Good agreement has been obtained between numerical simulations and experimental results. The paper is constructed as follows. The developed array antenna design and simulation including the single element, $1 \times 2$ and $1 \times 4$ linear arrays are presented in section 2 . The fabrication and measurements are discussed in section 3 . Finally, the work is concluded in section 4.

\section{Design and Simulation:}

The geometry of an antenna element is optimized and is shown in Figure (1) (in $\mathrm{mm}$ ). Rogers substrate [5], RT-Duriod $5880\left(\varepsilon_{\mathrm{r}}=2.2\right)$ single substrate is used with 62 mil thickness. U-shaped slotted patch is used to provide the dual-band for both the LTE and WLAN applications. Figure (2) shows that the reflection coefficient $S_{11}$ is $-23.83 \mathrm{~dB}$ at $3.5 \mathrm{GHz}$ with a frequency bandwidth of $75 \mathrm{MHz}$ (LTE frequency band), and is $20.88 \mathrm{~dB}$ with a frequency bandwidth of $80 \mathrm{MHz}$ at $5 \mathrm{GHz}$ (WLAN frequency band). This ensures good matching. Fig. 3 shows the meandering of the surface current on the radiating U-slot patch this result in an increase of the length of the equivalent surface current path. Fig. 4 shows that the gain is better than $7 \mathrm{dBi}$ with antenna efficiency of $93.43 \%$ at $3.5 \mathrm{GHz}$. The simulation also shows that the gain is $7.09 \mathrm{dBi}$ with antenna efficiency of $80 \%$ at $5 \mathrm{GHz}$. 


\subsection{Single Antenna Element}

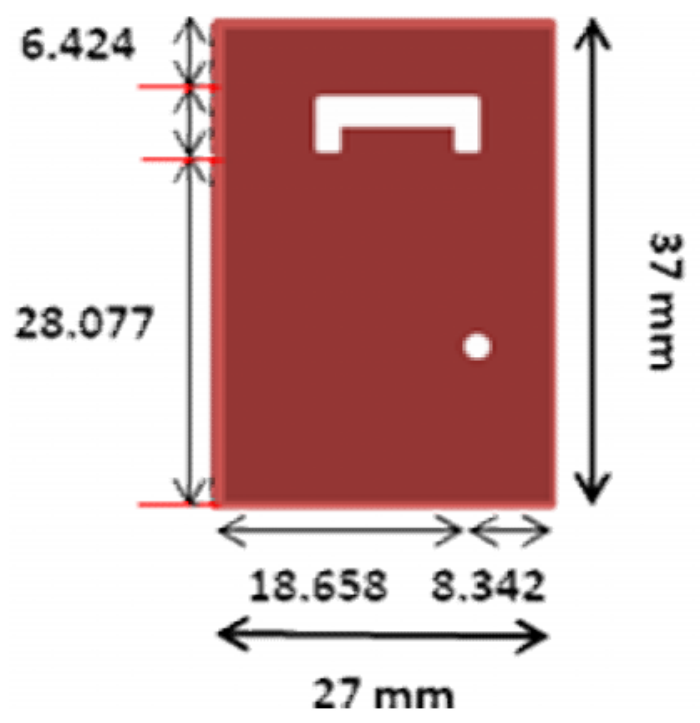

Figure (1)

Geometry of a $U$-slotted antenna element

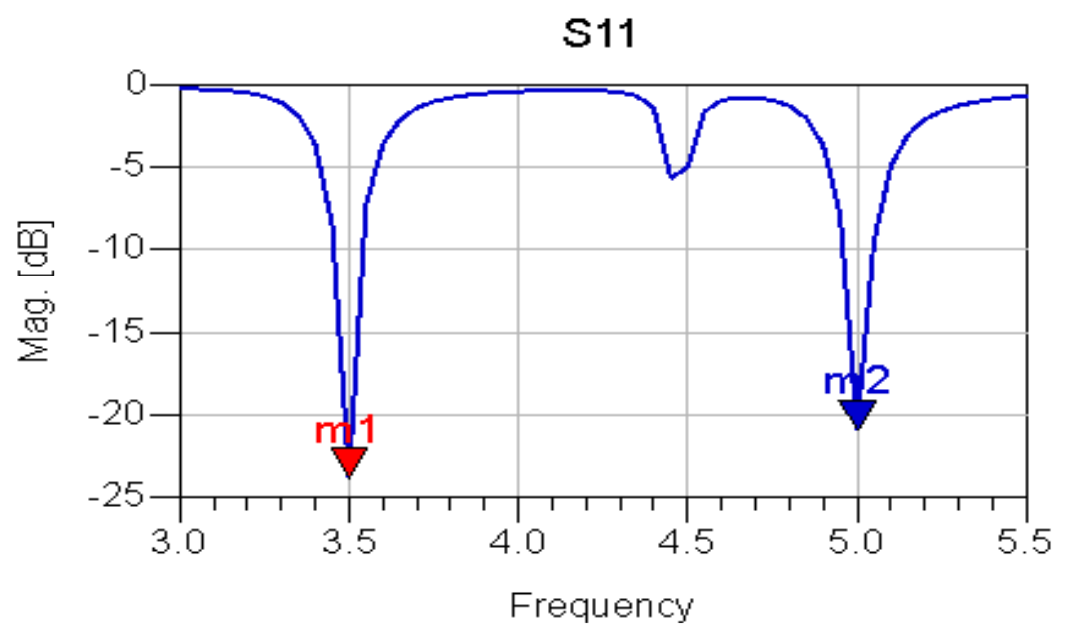

m1 Freq $=3.500 \mathrm{GHZ} S(1,1)=-23.834 \mathrm{~dB}$

$\mathrm{m} 2$ Freq $=5.000 \mathrm{GHZ} \mathrm{S}(1,1)=-20.884 \mathrm{~dB}$

Figure (2)

Single element reflection coefficient $S_{11}$ 


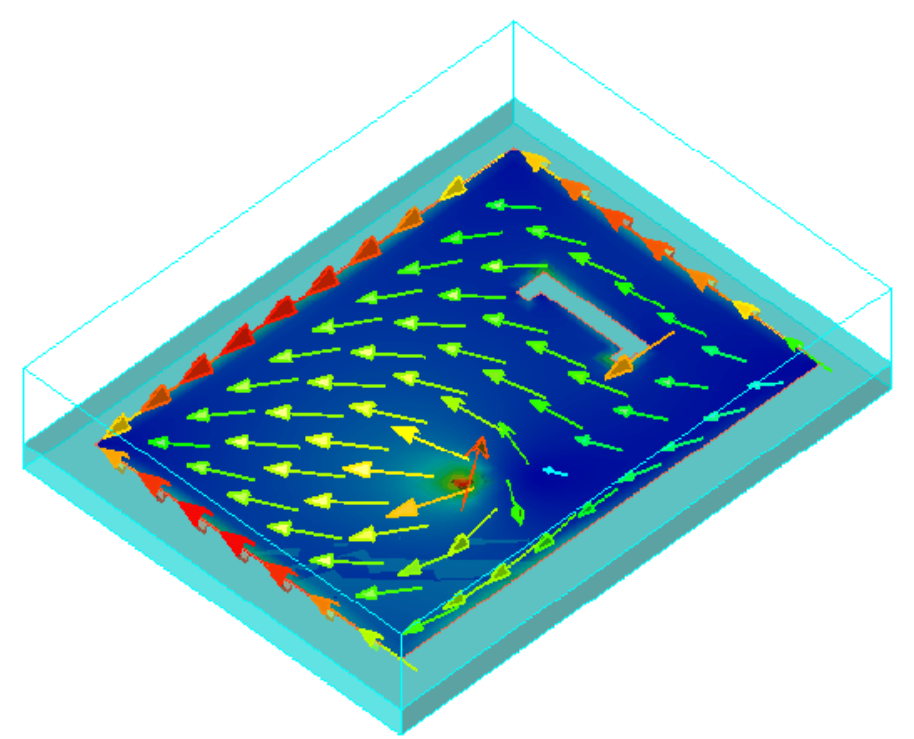

Figure (3)

Meandering of the surface current on the radiating $U$-slotted patch

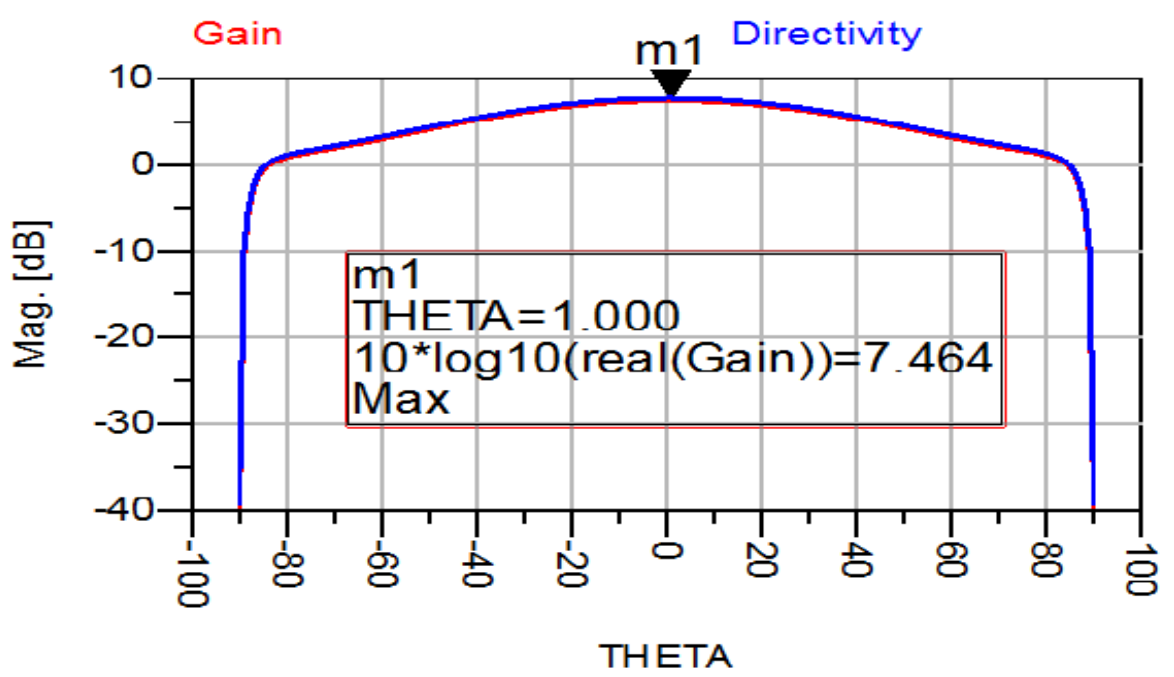

Figure (4)

Single element gain is better than $7 \mathrm{dBi}$ with antenna efficiency of $93.43 \%$ at $3.5 \mathrm{GHz}$ 


\subsection{1x2 Linear Array Antenna}

Figure (5) shows the $1 \times 2$ linear array antenna with edge to edge separation of $10 \mathrm{~mm}$ and separate feeding ports. Figure (6) shows the reflection coefficients $S_{11}$ and $S_{22}$. Figure (7) shows that the coupling between ports 1 and 2 is better than $-18.61 \mathrm{~dB}$ at $3.5 \mathrm{GHz}$ and $-16 \mathrm{~dB}$ at $5 \mathrm{GHz}$. Fig. 8 shows that the gain is better than $9.5 \mathrm{dBi}$ with antenna efficiency of $98.03 \%$ at $3.5 \mathrm{GHz}$.

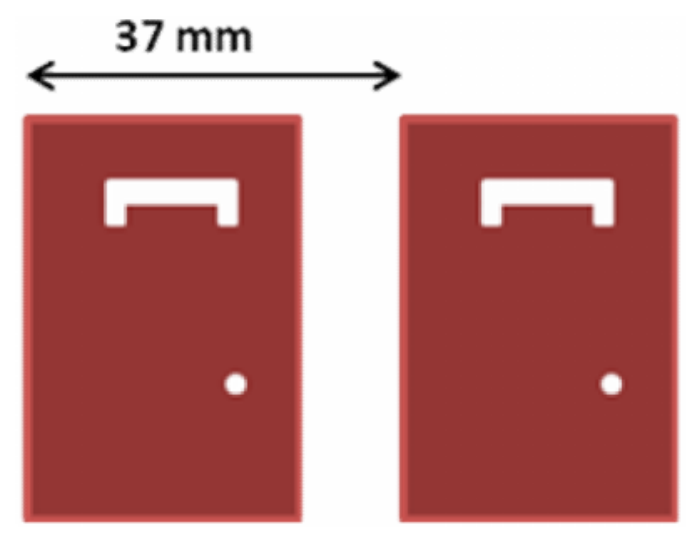

Figure (5)

The $1 \times 2$ linear array antenna

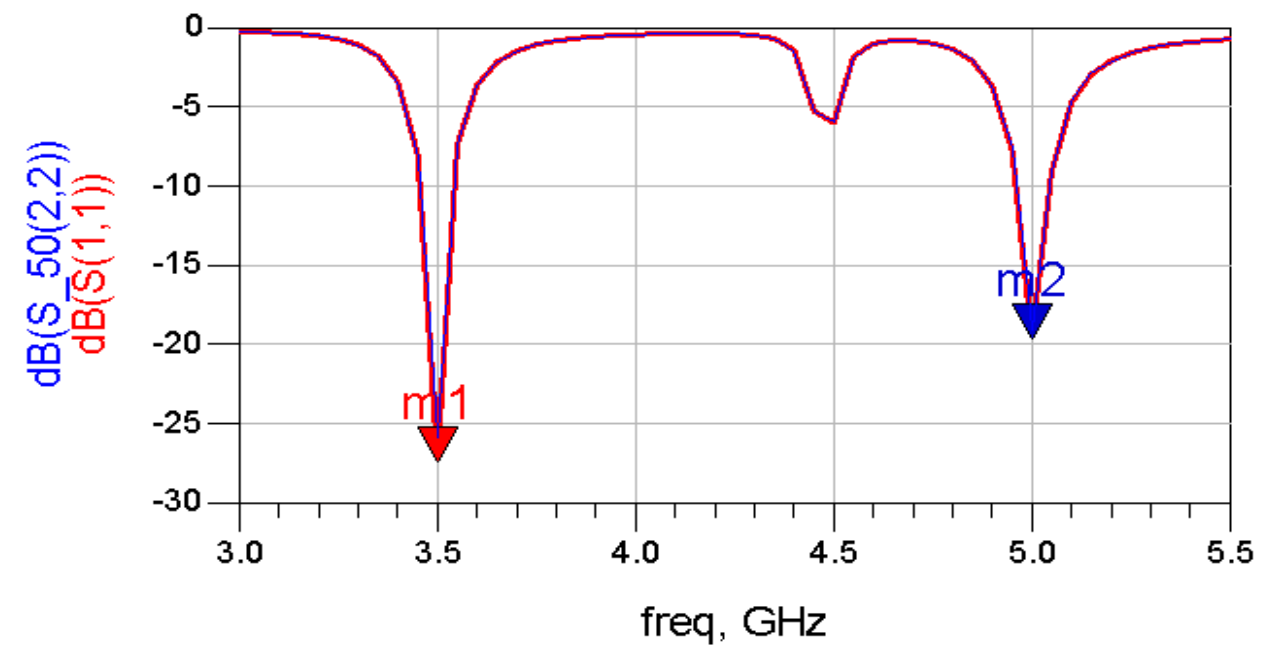

m1 Freq $=3.500 \mathrm{GHZ} S(1,1)=-27.394 \mathrm{~dB}$

$\mathrm{m} 2$ Freq $=5.000 \mathrm{GHZ} \mathrm{S}(\mathbf{1 , 1})=-19.618 \mathrm{~dB}$

Figure (6)

The reflection coefficients $S_{11}$ and $S_{22}$ 


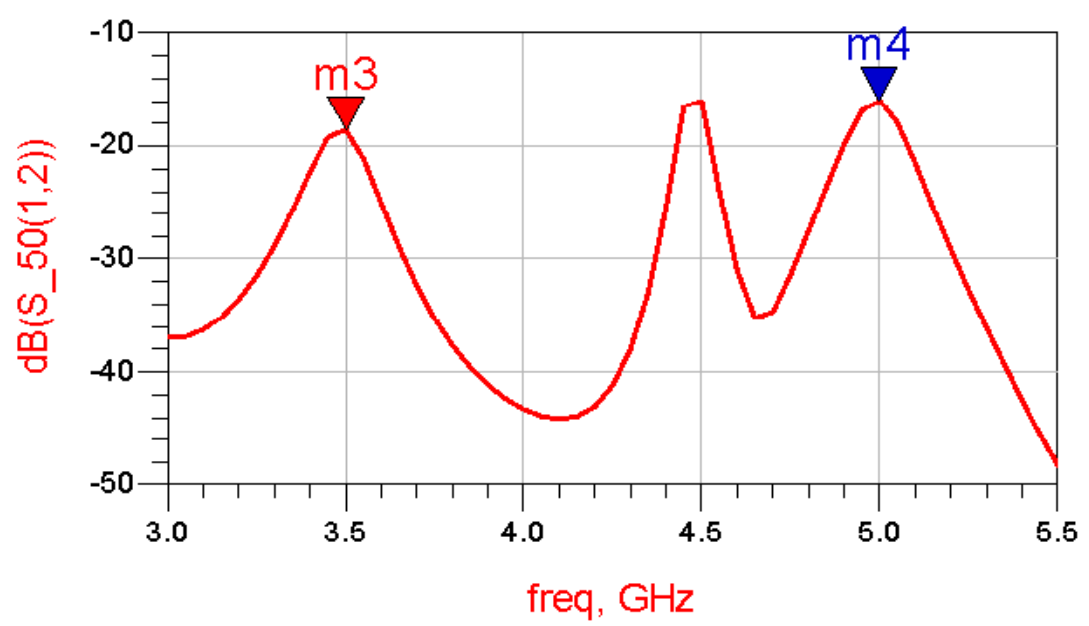

$\mathrm{m} 3$ Freq $=3.500 \mathrm{GHZ} \mathrm{S}(1,2) \&(2,3) \&(3,4)=-17.835$

$\mathrm{m} 4$ Freq $=5.000 \mathrm{GHZ} \mathrm{S}(1,2) \&(2,3) \&(3,4)=-15.794$

Figure (7)

The coupling coefficients $S_{12}$

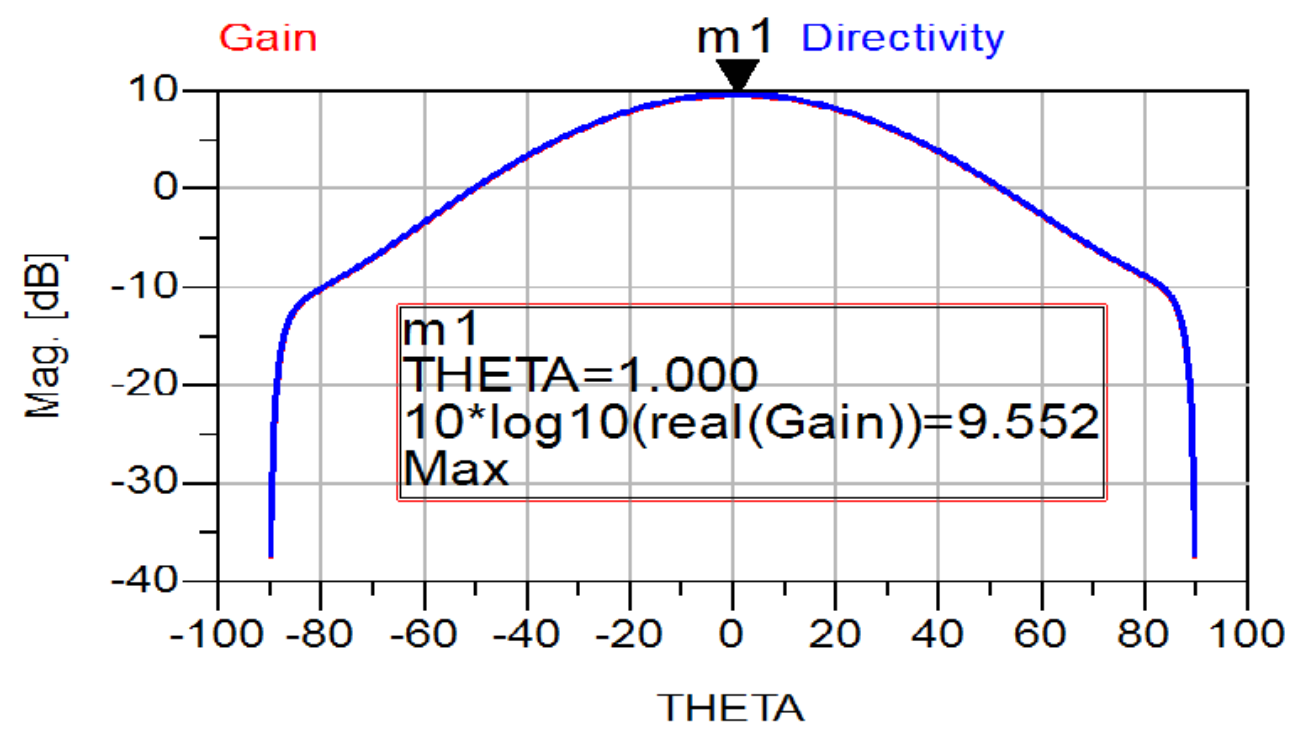

Figure (8)

The $1 \times 2$ linear array gain is better than $9.5 \mathrm{dBi}$ with antenna efficiency of $98.03 \%$ at $3.5 \mathrm{GHz}$ 


\subsection{1x4 Linear Array Antenna}

Figure (9) shows the $1 \times 4$ linear array antenna. Figure (10) shows the reflection coefficients $\mathrm{S}_{11}-\mathrm{S}_{44}$. Fig. 11 shows the coupling between different ports at $3.5 \mathrm{GHz}$ and 5GHz. Fig. 12 shows that the gain is better than $12.33 \mathrm{dBi}$ at $3.5 \mathrm{GHZ}$. Fig 13 shows the antenna efficiency of $98.46 \%$ at $3.5 \mathrm{GHz}$.

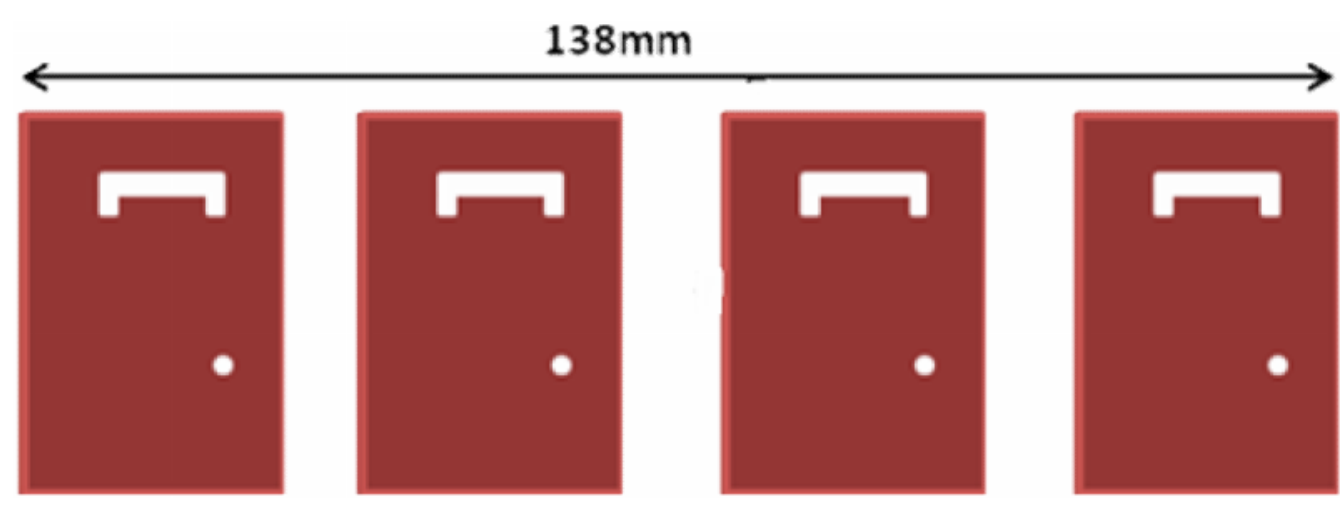

Figure (9)

The $1 x 4$ linear array antenna

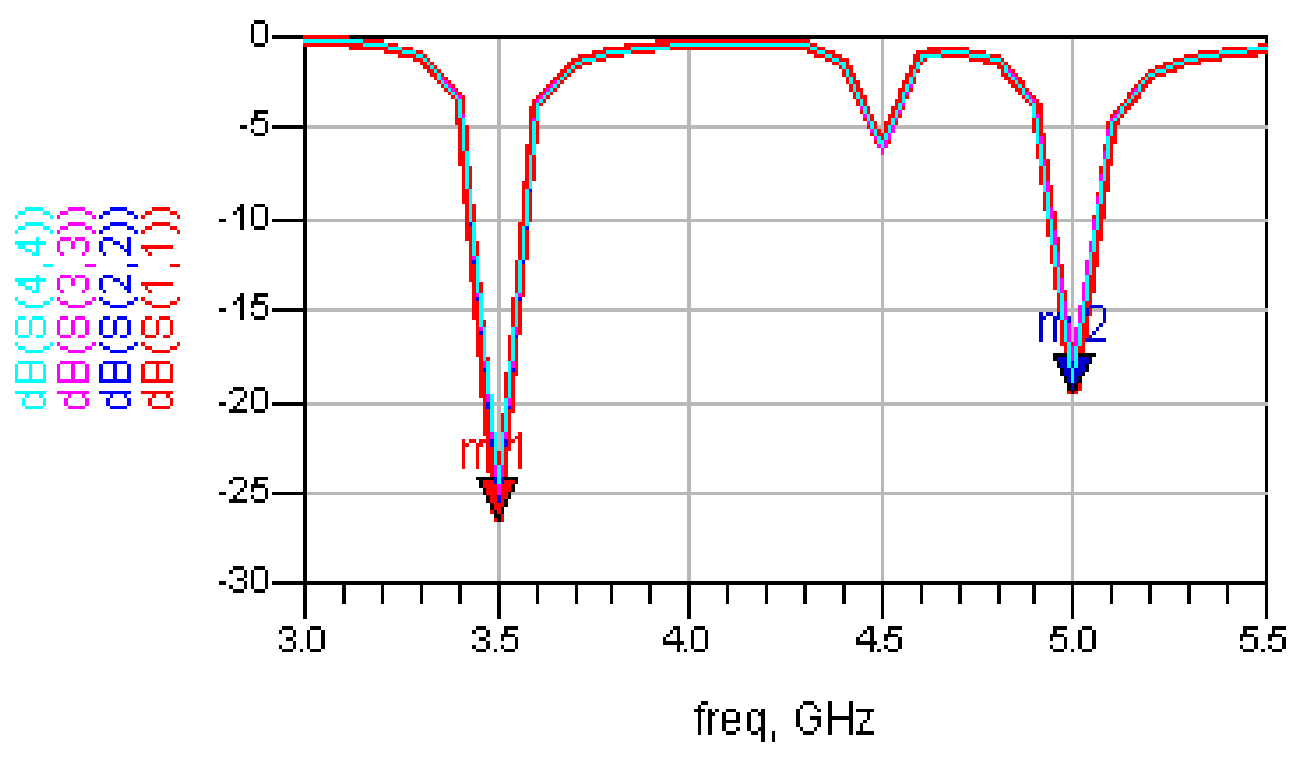

Figure (10)

The reflection coefficients $S_{11}-S_{44}$ 


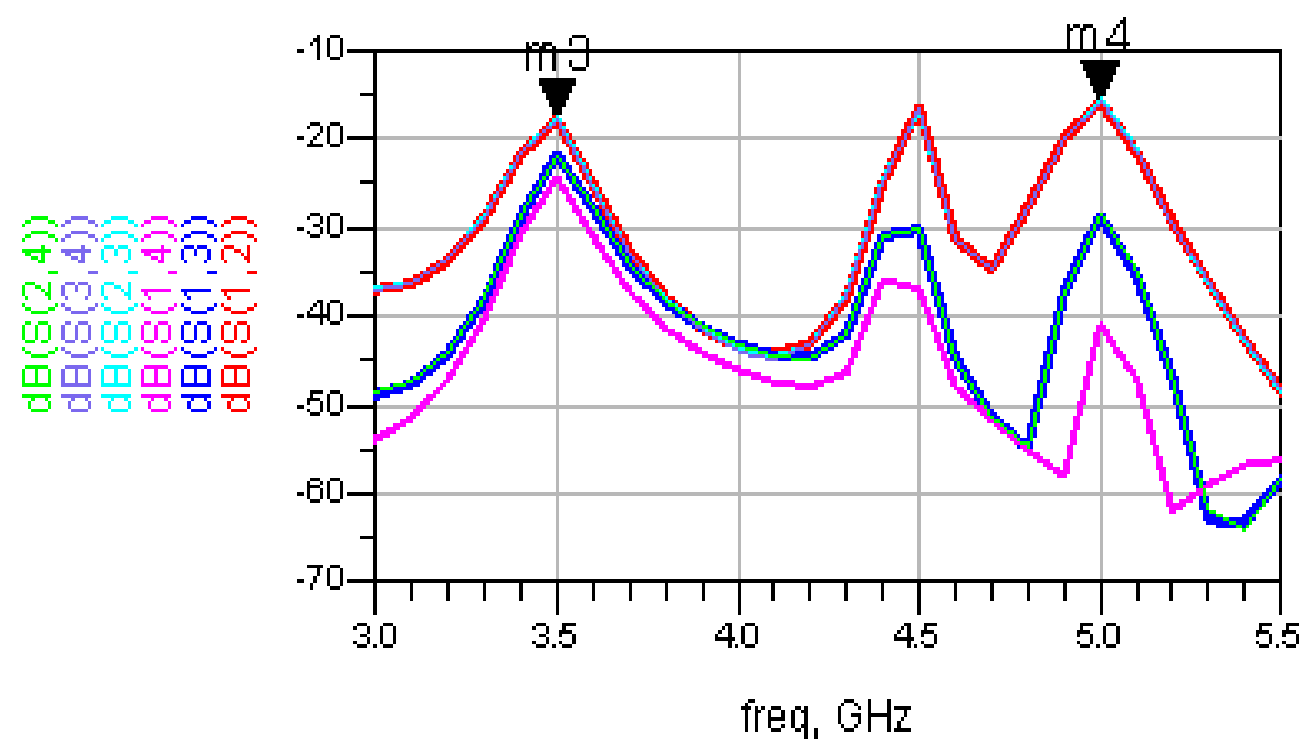

m3 Freq $=3.500 \mathrm{GHZ} \mathrm{S}(1,2) \&(2,3) \&(3,4)=-17.835$

$\mathrm{m} 4$ Freq $=5.000 \mathrm{GHZ} \mathrm{S}(1,2) \&(2,3) \&(3,4)=-15.794$

Figure (11)

The coupling between different ports at $3.5 \mathrm{GHz}$ and $5 \mathrm{GHz}$

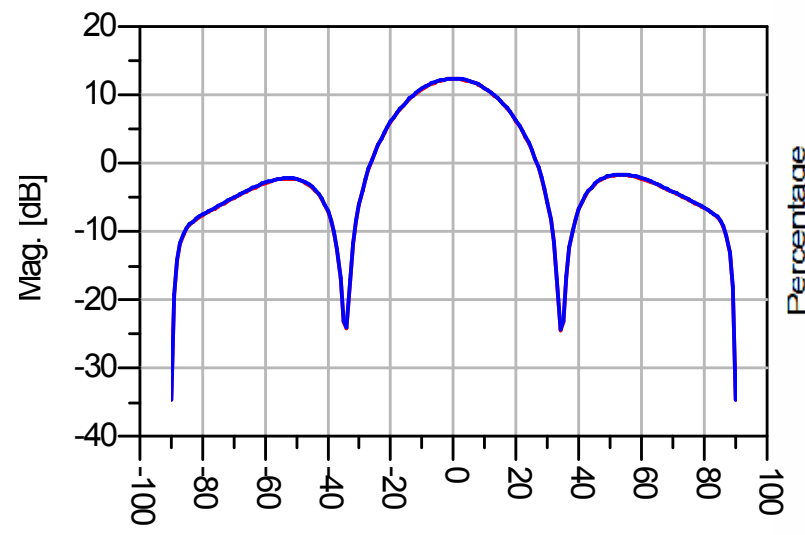

THETA

Figure (12)

The $1 \times 4$ linear array antenna gain at $3.5 \mathrm{GHz}$

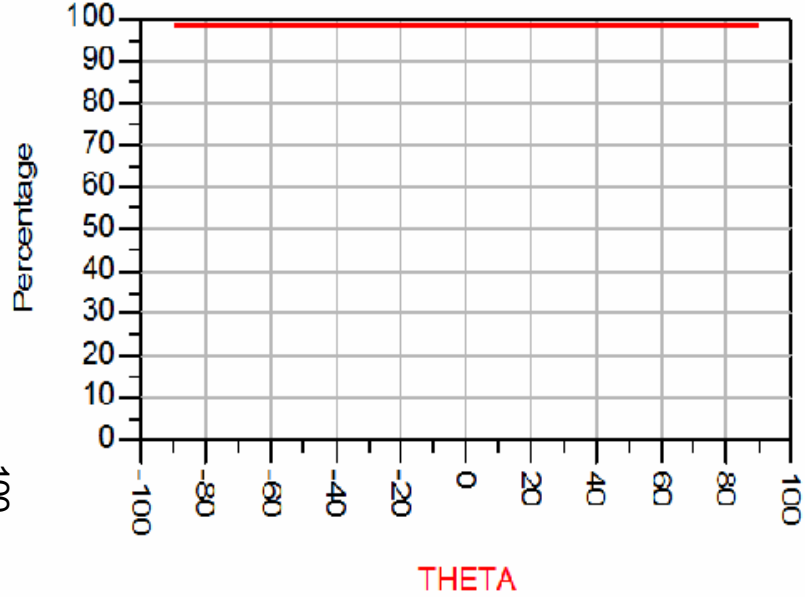

Figure (13)

The $1 x 4$ linear array antenna efficiency of $98.46 \%$ at $3.5 \mathrm{GHz}$ 


\section{3- Fabrication and Measurements:}

Figure (14) shows the fabricated single element. Figure (15) shows that the measured $\mathrm{S}_{11}$ is equal to $-18.98 \mathrm{~dB}$ at $3.5 \mathrm{GHZ}$ with a band width of $70 \mathrm{MHZ}$ and equals to $27.44 \mathrm{~dB}$ at $5 \mathrm{GHZ}$ with a band width of $90 \mathrm{MHZ}$. Good agreement between the measured and the simulation results is achieved for the single element. Figure (16a) shows the fabricated 1x2 linear sub-array, Figure (16b) shows the measured reflection coefficients $S_{11}$ and $S_{22}$. Figure (16c) shows the measured coupling coefficient $S_{12}$. Figure (17a) shows the compact fabricated $1 \times 4$ linear sub-array. Figure $(17 \mathrm{~b})$ shows the measured reflection coefficients $S_{11}, S_{22}, S_{33}$ and $S_{44}$. Figure (17c) shows the measured coupling coefficients $S_{12}, S_{13}$ and $S_{14}$. Figure (17d) shows the measured coupling coefficients $S_{23}$ and $S_{24}$. Figure (17e) shows the measured coupling coefficients $S_{34}$.
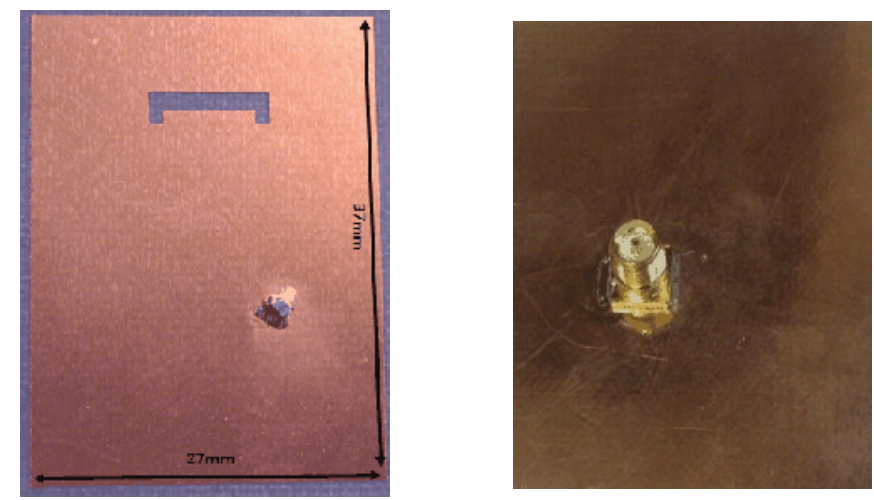

Figure (14)

The fabricated single element

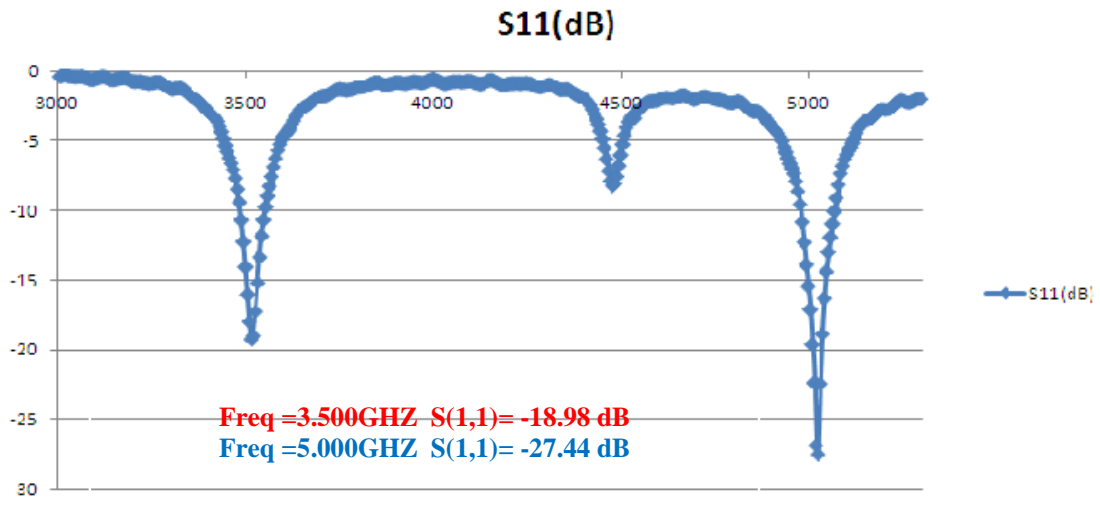

Figure (15)

The measured $S_{11}$ 


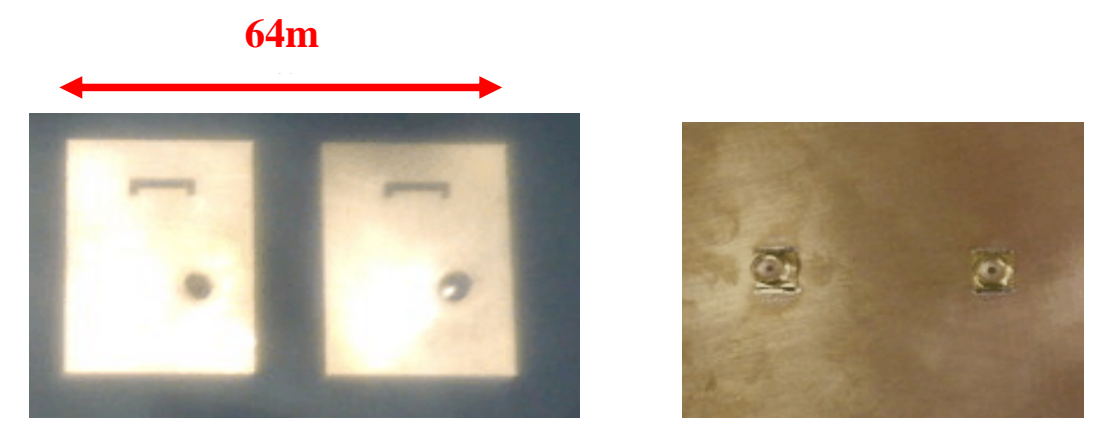

(a)

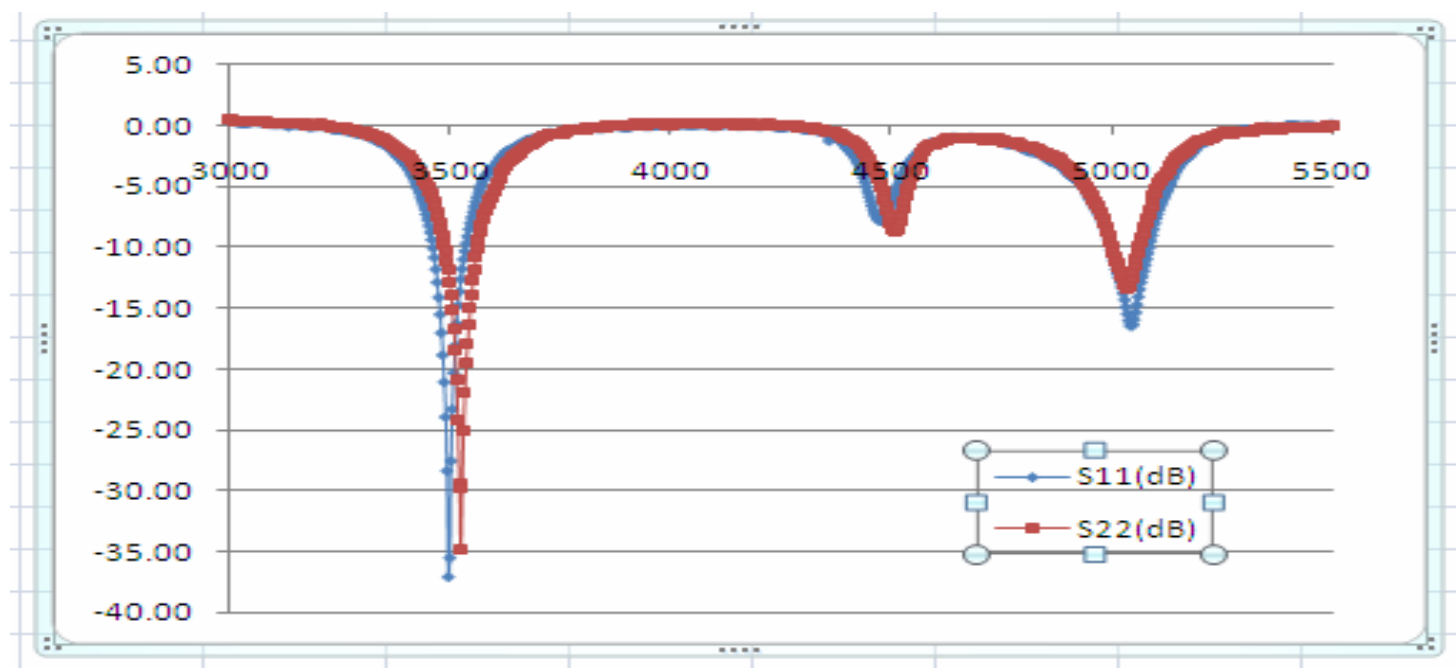

(b)

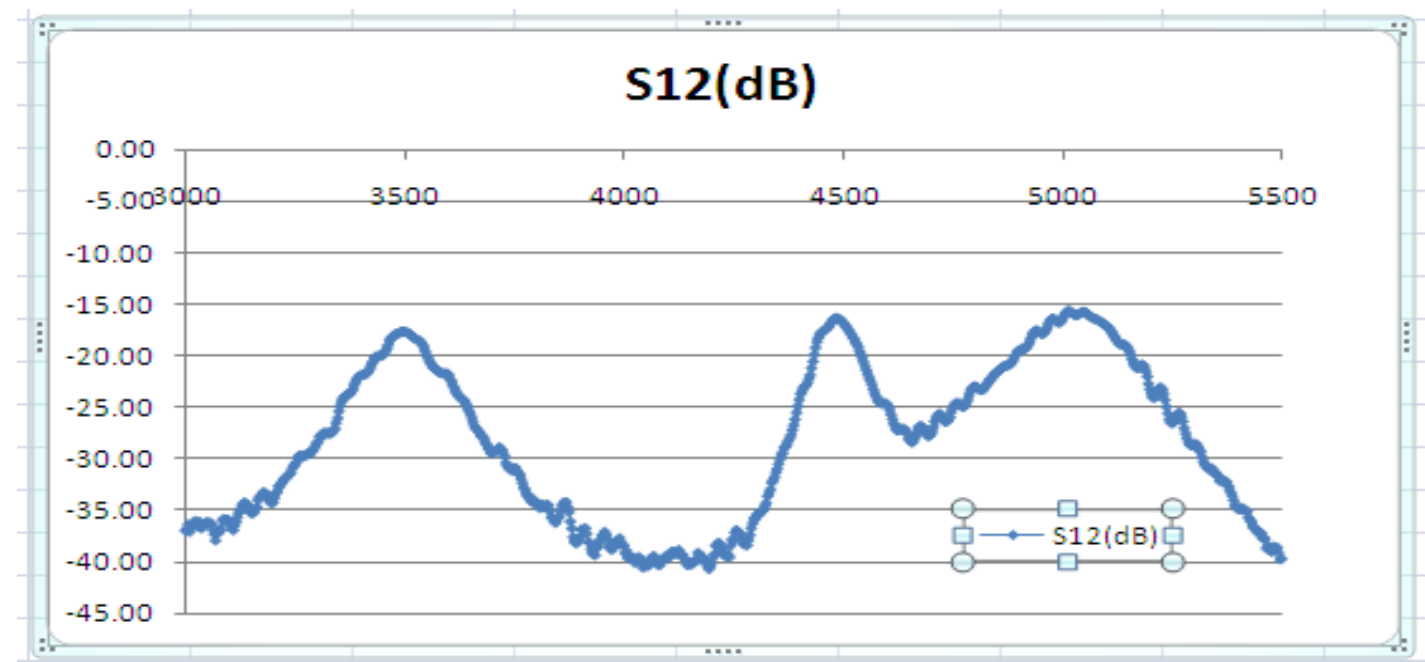

(c)

Figure (16) 
(a) shows the fabricated 1x2 linear sub-array, (b) shows the measured reflection coefficients $S_{11}$ and $S_{22}$. (c) shows the measured coupling coefficient $S_{12}$.

\section{$138 \mathrm{~mm}$}
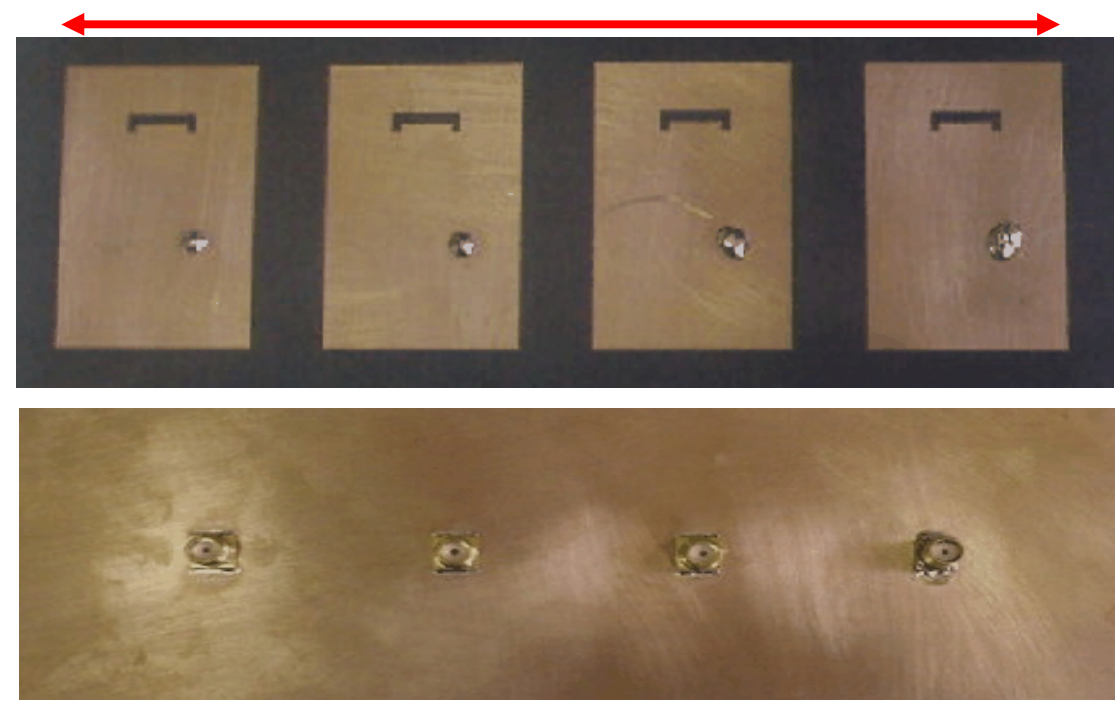

(a)

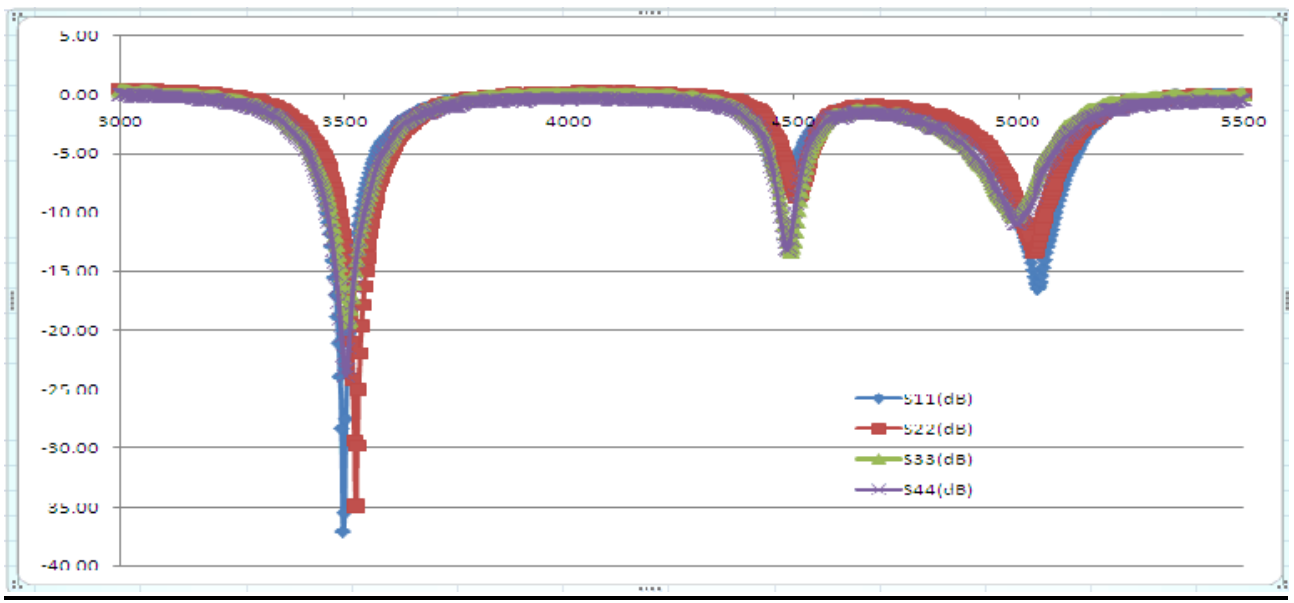

(b)

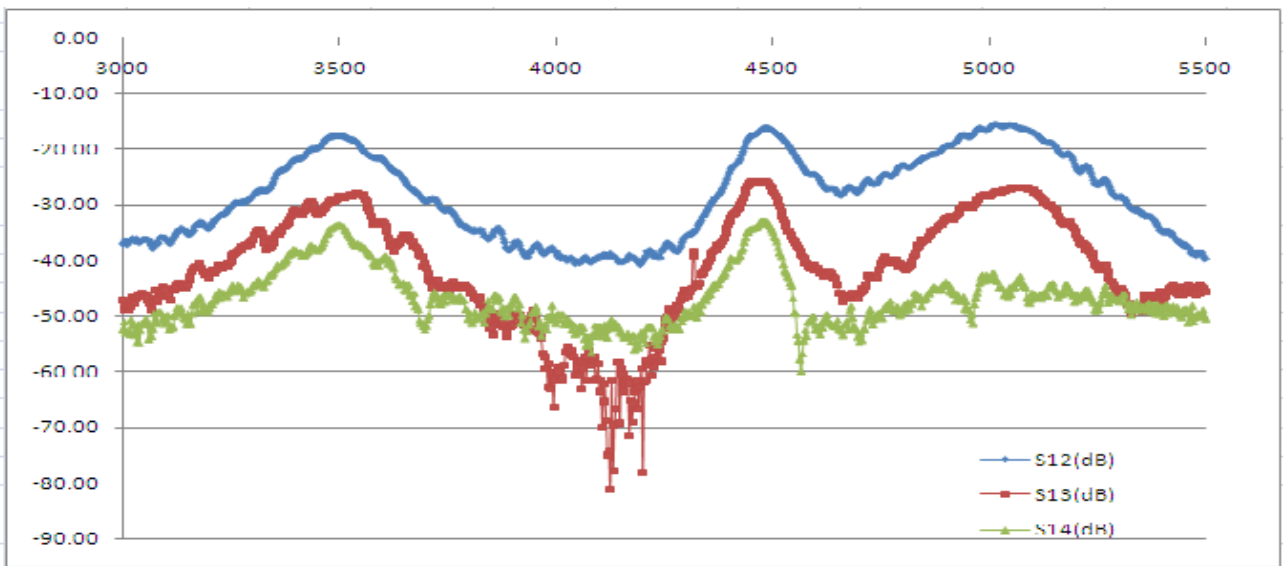


(c)

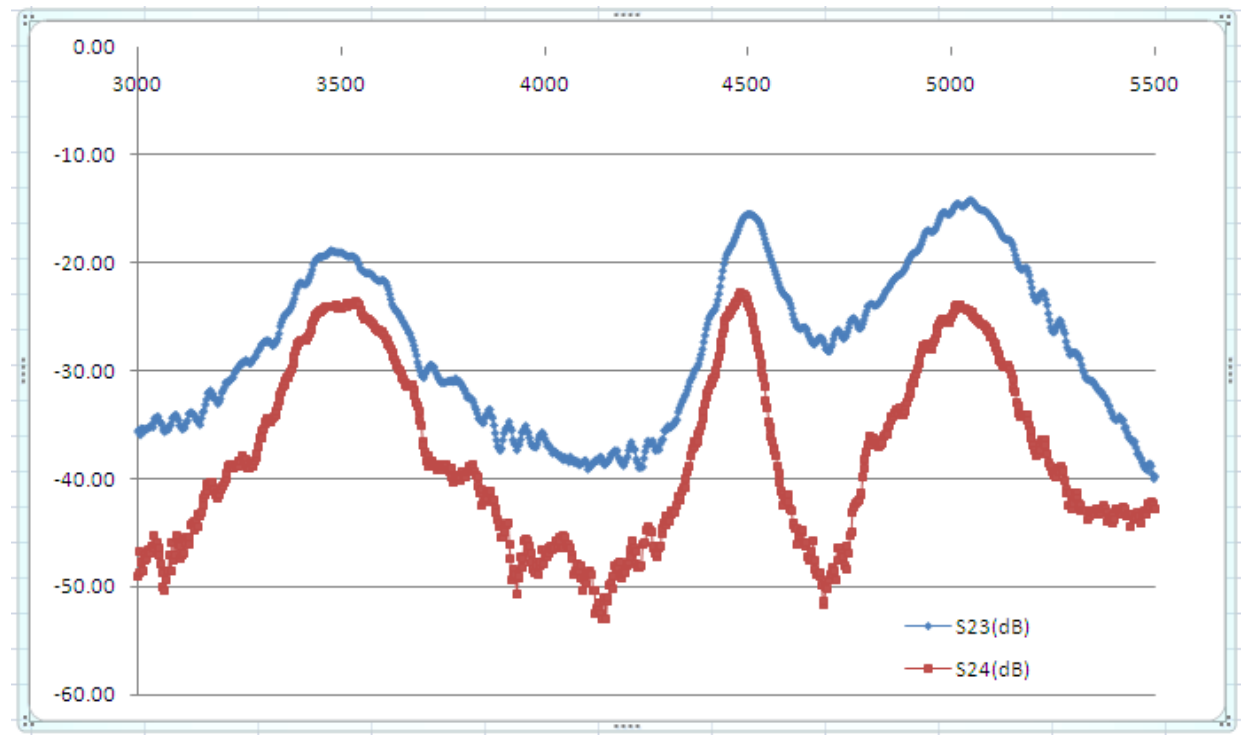

(d)

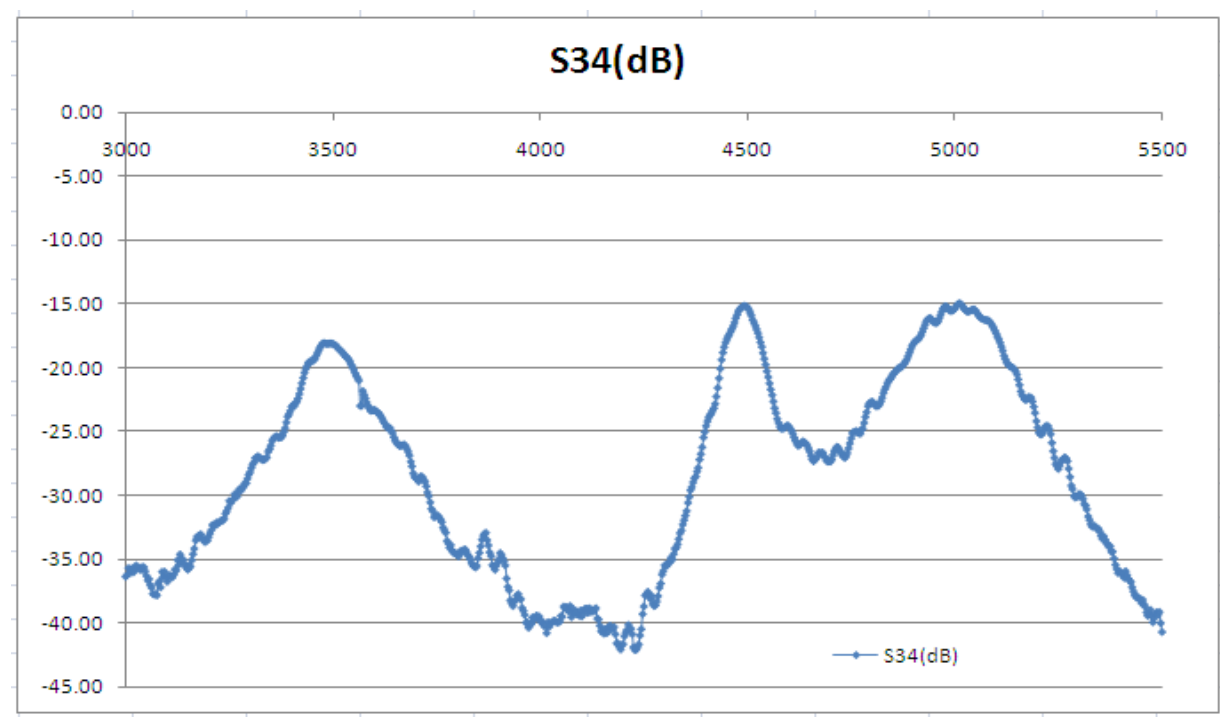

(e)

Figure (17)

(a) shows the compact fabricated $1 \times 4$ linear sub-array. (b) shows the measured reflection coefficients $S_{11}, S_{22}, S_{33}$ and $S_{44 .}$ (c) shows the measured coupling coefficients $S_{12}, S_{13}$ and $S_{14}$. (d) shows the measured coupling coefficients $S_{23}$ and $S_{24}$. (e) shows the measured coupling coefficients $S_{34}$. 


\section{4- Conclusion:}

A compact dual-band microstrip patch array antenna that is suitable for the MIMO 4G LTE and WLAN has been developed. Single element, prototype is fabricated and measured. 1x 2 and 1x4 linear sub-arrays are designed, fabricated and measured. Good agreement between the measured and simulated results are achieved. The achieved results satisfy the requirements of both the MIMO 4G LTE and WLAN antenna systems.

\section{$\underline{\text { Acknowledgement : }}$}

The authors would like to acknowledge Dr. Hesham Nabil, Dr.Ayman El-tager, Eng. Ahmed Elalemey for their great efforts and valuable contributions during the manufacturing process at the microstrip lab of the MTC.

\section{References:}

[1] Advanced Design System, 2008 Momentum Software Manual, Agilent Technologies, CA: Palo Alto, 2008.

[2] G. J. Foschini, "Layered space-time architecture for wireless communication in a fading environment when using multi-element antennas," Bell Labs Technical Journal, Autumn 1996, pp. 41-59.

[3] Martin Sauter, Beyond 3G-Bringing Networks, Terminals and the Web Together, John Wiley \& Sons Ltd, 2009.

[4] Constantine A. Balanis, Antenna Theory Analysis and Design, Third Edition, by John Wiley \& Sons, Inc. 2005.

[5] http//:www.rogerscorporation.com. 